\title{
Integrated reporting of agricultural business entities as a factor of sustainable development in the Volgograd Region
}

\author{
Victor Melikhov \\ Volgograd State \\ Agrarian University, \\ Faculty of Economics \\ Melikhov707@yandex.ru
}

\author{
Yulia Kusmartseva \\ Volgograd State University, \\ Institute of Economics and Finance \\ Volgograd, Russia \\ kfbd@volsu.ru
}

\author{
Tatiana Chekrygina \\ Volgograd State \\ Agrarian University, \\ Faculty of Economics \\ Volgograd, Russia \\ dek_ekonomvolgau@mail.ru
}

\begin{abstract}
The article represents the current methodological base and the author's concept for the preparation of integrated reporting of agro-holdings, an analysis of the conformity of public reporting of agribusiness entities was made, a "point of growth" in the development of methodology for implementing block-technology in accounting practices was singled out, a roadmap for organizing the formation of integrated reports, provides recommendations for improving the process of preparation and quality of integrated reporting for the mediumterm period, the structure of the integrated report
\end{abstract}

Keywords- integrated reporting, integrated accounting system, sustainable development, agroindustrial holdings, blockchain, economic security

\section{INTRODUCTION}

In the current conditions of agribusiness development in the Volgograd region, intensive development of both agroindustrial production (technology, selection) and improvement of the management system by agrarian economic entities for solving import substitution problems, economic security of the region during the application of sanctions to Russia and a reciprocal food embargo are required $[1 ; 2]$. A special role in solving problems on sustainable development is assigned to large diversified integrated agro-industrial holdings. We believe that the reporting of such structures as an element of effective management should be substantially more informative, relevant and qualitative [3].

In previous author's studies, the genesis of the concept of integrated reporting and the discussion of authors on the topic presented in the article were presented [3].

At the present stage, the task is to develop the concept, methodology and technology for the formation and verification of integrated reporting (here in after IR) to form the integrated reporting for large integrated structures, and in particular, to elaborate the methods and ways of obtaining information for reports, to adopt the strategy in order to organize a system of single, unified accounting. There are various works and issues relating to the theoretical methodology elements, e.g. an International Standard for Integrated Reporting, etc., but in the practical methodology, which is focused on solving practical problems, and aimed at implementing the concept of integrated reporting, there is a shortage of programs (algorithms), tools (techniques and 
methods) correlating different accounting systems in a single system and forming a unified reporting based on accounting data that are generated in the system.

Conducting our research, we aim to develop and propose to use tool that helps to develop the methodology of formation and verification of integrated reporting for agricultural holdings of the Volgograd region (Russia as a whole).

To achieve the purpose we have set the following objectives:

1. To analyze the public reporting packages of the largest agro-holdings of the Volgograd region for 2016 year for compliance with international and Russian accounting and reporting standards.

2. To propose a structure for system of the integrated report of the economic subject of agribusiness on the basis of analysis and generalization of the methodological basis for preparing integrated reports on a global scale;

3. To determine the "points of growth" of methodology development for integrated reporting and the practices of applying the concept of integrated reporting in the form of "blockchain" technology. To present advantages and disadvantages in the aspect of integrated reporting;

4. To develop and recommend a road map of the process of preparing the integrated reporting for agricultural holdings (to determine the logical structure, procedures, objects, forms, means, methods, results of the accounting and control process and the timing to implement the project: phases, stages, steps).

5. To recommend actions to develop the methodology organizing the system of preparing and forming the process of integrated reporting for the medium-term period (2018-2020 years): the structure of the report, accounting policies, technical regulations, verification of data.

\section{MATERIALS AND MeTHODS (MODEL)}

Having analyzed the best world practice of preparing integrated reporting of the Group companies, we can notice that not all methods are qualitative and efficient. Scientific research should be aimed at solving methodological, organizational and technical problems that help to find principles for achieving the goal of preparing, presenting and verifying of qualitative relevant and pertinent uniform reporting.

The main objective for the effective implementation of the integrated reporting project is to justify the methodology and technical aspects of the formation of a single IR (elements, approaches, principles) aimed at obtaining a relevant data format).

We use a conceptual approach as the main research method. To implement it we analyze the phenomena and processes associated with the process of preparing integrated reports, as well as reveal a complex of their elements and relationship between the constitutive elements of the integrated reporting concept. It is important to introduce the character and the limits of the interactions and to determine the processes of data convergence from different accounting systems. This method is based on observation, analysis and synthesis of theoretical opinions on the research topic.

The second approach, constituting a single complex, is a formal one that promotes establishing strong connection between the elements of coherently integrated accounting through formalized algorithm organizing the system.

\section{RESULTS AND DISCUSSION}

We believe that the formation of integrated reporting by economic entities (especially agribusiness entities) directly affects their economic security and leads to the sustainable development of subjects and the region as a whole [8,9].

According to the Table 1, the level of the agroindustrial enterprises in the Volgograd region reports compliance with IFRS is not very high - 38\%, $19 \%$ of agricultural holdings prepare reports in accordance with the Guidelines for reporting on sustainable development. The Global Reporting Initiative (G3.1), and $26 \%$ of companies make reports in accordance with the Draft International Standard for integrated Reporting.

We assume that in the near future, Russia will expand the scale of the use of these two international standards (IR and GRI) in connection with existing global trends, as well as in connection with changing the national regulatory framework.

This process will increase the competitiveness of agribusiness entities in the Volgograd region.

TABLE 1. Compliance of agro-industrial holdings in the Volgograd

\begin{tabular}{|c|c|c|c|c|c|}
\hline Enterprises bist & $\begin{array}{l}\text { Compliance } \\
\text { with IFRS }\end{array}$ & $\begin{array}{l}\text { Compliance } \\
\text { with the } \\
\text { Management } \\
\text { for sustainable } \\
\text { development } \\
\text { (GRI) }\end{array}$ & $\begin{array}{c}\text { Compliance } \\
\text { with IIRC } \\
\text { (IR-reporting) }\end{array}$ & $\begin{array}{c}\text { Compliance } \\
\text { with RAS }\end{array}$ & $\begin{array}{c}\text { Internal audit } \\
\text { reports }\end{array}$ \\
\hline $\begin{array}{l}\text { Holding } \\
\text { "Helio-Paks" company }\end{array}$ & + & - & + & + & + \\
\hline $\begin{array}{l}\text { LLC "Vipoyl" (Holding } \\
\text { "Vipoyt) }\end{array}$ & + & - & + & + & + \\
\hline $\begin{array}{l}\text { Agricultural holding } \\
\text { "Novoanninskiy" }\end{array}$ & - & - & - & + & + \\
\hline $\begin{array}{l}\text { Agribusiness "Zarya" } \\
\text { (holding } \\
\text { "PomidorProm") }\end{array}$ & - & - & - & + & - \\
\hline $\begin{array}{l}\text { CJSC "Krasnodonskoye" } \\
\text { (Mriya "Kopitaniya") }\end{array}$ & + & + & + & + & + \\
\hline $\begin{array}{l}\text { LIC } \\
\text { "Gorodishchenskaya } \\
\text { Poultry" }\end{array}$ & - & - & - & + & - \\
\hline $\begin{array}{l}\text { LLC } \\
\text { Kamyshinskaya" }\end{array}$ & - & - & - & + & - \\
\hline $\begin{array}{l}\text { CJSC } \\
\text { Vostok" }\end{array}$ & - & - & - & + & + \\
\hline $\begin{array}{l}\text { Agricultura1 holding } \\
\text { "Agro Invest" }\end{array}$ & + & + & - & + & + \\
\hline $\begin{array}{ll}\text { Agro } & \text { Holding } \\
\text { "Volgograd" }\end{array}$ & - & - & - & + & - \\
\hline $\begin{array}{l}\text { Agricultural holding } \\
\text { "Geteks" }\end{array}$ & + & - & - & + & + \\
\hline $\begin{array}{l}\text { Agricultural } \\
\text { "Terra-Invest" holding }\end{array}$ & - & - & - & + & - \\
\hline $\begin{array}{l}\text { Group of companies } \\
\text { "Agricultural holding" }\end{array}$ & - & - & - & + & - \\
\hline $\begin{array}{l}\text { Agro Holding Ltd. } \\
\text { "Nagavskoe" }\end{array}$ & - & - & - & + & - \\
\hline $\begin{array}{l}\text { LLC "Agricultural } \\
\text { holding Povolzhje" }\end{array}$ & - & - & - & + & - \\
\hline $\begin{array}{l}\text { JSC "Gardens of } \\
\text { Pridonye" }\end{array}$ & + & + & + & + & + \\
\hline
\end{tabular}

In the research process, we conducted a review of all legal documents on integrated reporting in the global and national scale and presented the structure of the integrated report of the agricultural holding with the details of the business model elements (fig 1). The methodological aspects of organizing the system of integrated reporting for agricultural holdings have 
their own specifics, as different industries have different business models, business strategies and the mechanisms of value creation

Further it is important to consider the potential IT tools that we propose to use when forming the integrated reporting of agribusiness entities and for its verification. One option is blockchain, an innovative technology that has a huge potential, which can lead to significant transformations in industries related to accounting (reporting), audit, control, and can increase their effectiveness [11]. We can highlight the advantages of this technology for the IR system: reducing costs, eliminating duplicate information, increasing reliability.

The agribusiness entity is developing a new approach, where both the business strategy and the technology development strategy are defined in parallel. It is important to analyze the key aspects of the impact of blocking technology on the mechanism of formation of coherent-integrated reporting.

We have analyzed the advantages and disadvantages of this technology for the process of the preparation, presentation and verification of integrated reporting:

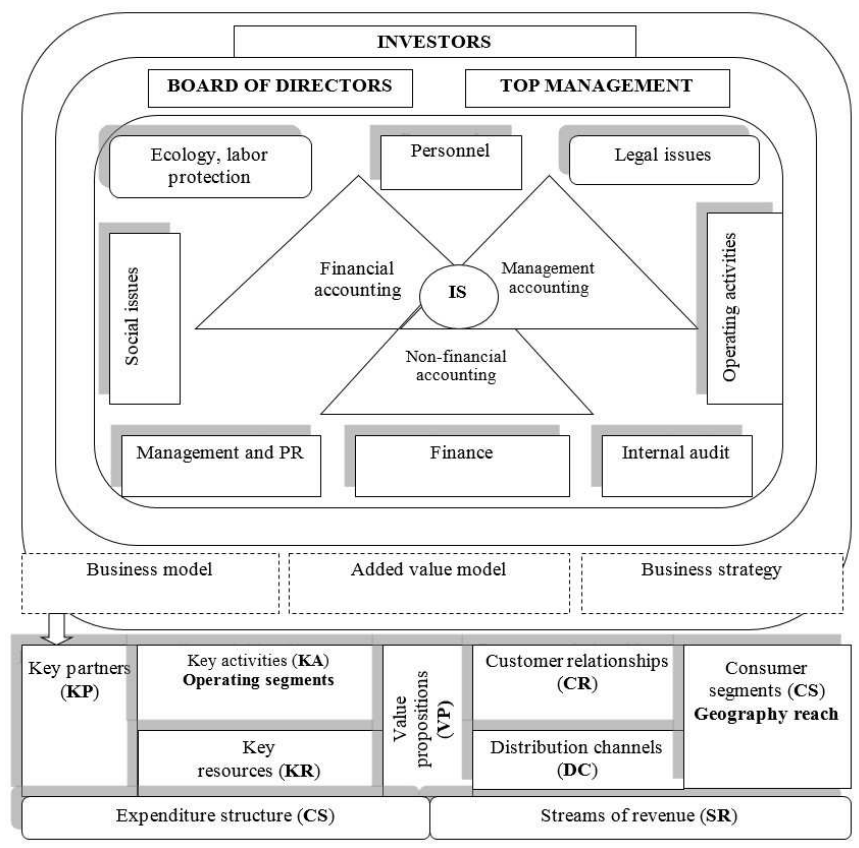

Fig. 1. Structure of agro-industrial holding integrated report with detailed business model elements:[3;8]

\section{Advantages:}

1. Reliability (resiliency, scalability, technology safety and recoverability)

2. Increasing the efficiency of internal operation (cost saving, improving the quality of reports and interacting with stakeholders)

3. Management (clear control, technology management). It is important to identify who possesses identification information, roles and rights
4. Market (positive potential impact of blockchain technology of our market by means of IR system)

5. Cooperation (it is necessary to cooperate effectively with stakeholders)

6. Development planning of technologies (it is necessary to take note of blockchain in development planning of technologies for 3-5 years to avoid wasted costs)

Disadvantages:

1. Risk of disruption (blockchain can lead to a violation of the usual order of doing business, adjustment of business strategy)

2.Applicability (understanding the purpose of business application if blockchain is really a suitable technology for IR system)

To get result for integrated report preparation blockchain technology strategy should cover three main aspects:

- wasted effort exception (encrypted once sends information to a network including metadata which allows you to track each step that passes the file. This system reduces up to $80 \%$ of storage costs) $[12 ; 13]$

- adoption control (blockchain allows the users to create their own guarding test of digital identification. We can use our ID blockchain to get access to websites and applications, to sign digital documents etc.)

- integration with the current systems (the technology makes it possible to use it for storage of any information leading to creation of permanent distribution register. It is more secure than in traditional data bases that are operating by a third party).

In connection with the above the IT director and IR methodologist should operate the processes through blockchain effectively. To do this we recommend:

1. Determine the time required for the starting a transition project; 2. Calculate the investments in blockchain and identify valuable opportunities and competitive advantages; 3 . Develop a register for tracking significant changes (identify related field where blockchain technology initiatives are widely represented and rapidly developed); 4 . Determine the difficulty of implementation (difficulty of implementation is the key factor determining the deadlines. It will be more essential to establish cooperation between numerous participants and synchronize their interests than the ability to solve technical questions); 5. Describe the current situation (describe the current technological landscape. This measure allows to find out the applications which are likely affected by blockchain technologies in the short- and medium term); 6 . Develop the architecture variants (the development of architecture variants with divided internal and external functions will aid to minimize the errors at the design stage. Close cooperation of IT team with blockchain developers and architects will make it possible); 7. Implementation control of blockchain technologies (implementation planning and control; risks connected with blockchain technology; lack of influence over pace of implementation); 8. Risk identification 
and minimization (it is possible to identify, remove and minimize risks at all stages of design process technology by confirmation of feasibility of conceptual solutions and implementation of pilot projects); 9. Technology as a whole (none of technologies exist separately. It is essential to consider the latest tax, regulatory and lawful questions). It is important to prepare for the changes by involving consulting experts in the relevant field and including the appropriate level of flexibility in the chosen options of technological and business solutions;10. Integration of blockchain solutions with the current systems (blockchain can increase efficiency of key processes, such as transaction and data exchange). The current systems are of great significancy for business dealing today. So that it is essential to consider blockchain solutions in a broader context taking into account business technologies and processes in general for smooth and successful integration new technologies within existing. To do this it is important to size up impact of blockchain technology on business widely, to define business processes, to develop new regulations, management system and means of control.

The main objective of the actions for the main stage (phase 2) on organizing integrated accounting is the unification of financial accounting data, according with the management accounting system and the system of accounting other (nonfinancial) information. This implies developing and adopting a uniform chart of accounts of coherently integrated accounting, optimizing single for all units (components) of the agroholding account registers, reference books of analytics of revenue and expenses, internal management reports.

Thus, it is important to develop an accounting policy for the purposes of the coherently integrated accounting, unifying preliminarily principal statements of accounting policies of the component companies (financial accounting, management accounting, and financial accounting) [14]. In our opinion, it is the base for correct (performing settings) converting of the national accounting data (or IFRS) in the chart of accounts according to coherently integrated accounting. To solve the set tasks within phase 2 (road map) we have identified two processes: 1. Determining report content (volume of recommended procedures; team building; defining the content of the sections and subsections of the report); 2. Text preparing process (development of the report structure; mechanism for the collection of information; procedures for preparing the report). (fig.2.)

In order to implement effectively the process of preparing single reports, it is important to observe the following conditions: a) the company operates in the field of sustainable development, thus the management supports the initiatives of sustainable development trend; b) the company is engaged in non-financial accounting; c) the employees understand the strategy and business model and have the opportunity to define essential aspects of the company; d) taking into account key performance indicators (financial and non-financial) at the company level; e) identifying its stakeholders and understanding their interests and needs; f) organizing the formalized system of data collection, including non-financial indicators in all segments.
At the same time the verification of the process, completeness and accuracy of the information, i.e. the fact of internal audit of non-financial data and interaction with stakeholders in the reports preparing process (feedback) is of high priority. Specifying the final stage of organizational activities, it is noteworthy that structures carrying out the verification of the content of coherently integrated report are to be provided with the justification of the first transition to a system of coherently integrated accounting and reporting (submission of the orders on transition to the IIRF (concept of

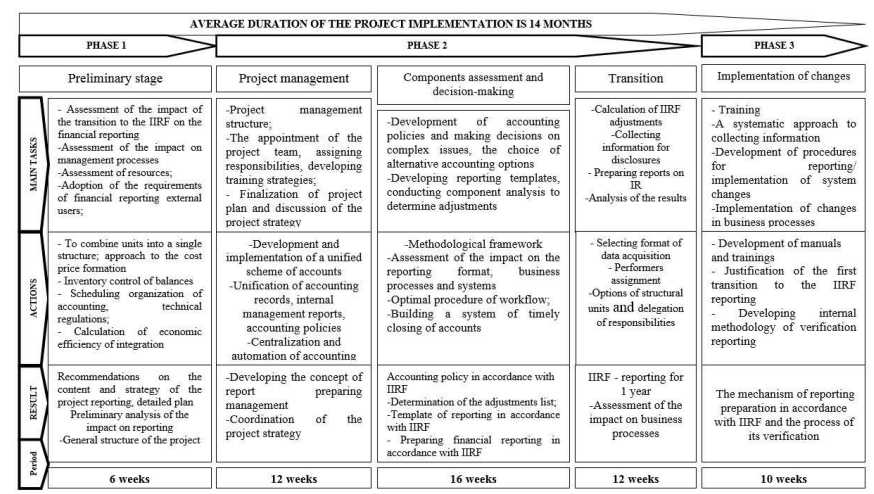

Fig. 2. "Road map" for the process implementation concerning formation of the integrated reporting.

international standard on integrated reporting), accounting policies, annual assessments of assets and liabilities (estimated values), books of transformational amendments, methodological basis of differences.

The study represents the author's approach to overcome bottlenecks in the preparation of IR and ways of methodology developing. We believe that the creation of effective procedures for document circulation, closing entries systems, formalized system of account collection directly affects the effectiveness of the integrated accounting system. Progressive system of accounting management of agribusiness entities assumes the existence of an electronic data interchange (option-technology «blockchain») which will increase the level of interaction between employees and group segments. The main goal is to shorten the term of coordination, accounting and control procedures, minimize delays and losses of primary documentation, adhere to the reporting closure period, exclude frauds and errors which increase the quality and correlation of accounting. The proposed procedures minimize the costs in the preparation of reporting in the medium term and improve interaction.

\section{CONCLUSION}

Preparing and presentation of integrated reporting is on of the most significant trends in the field of disclosure of data on the activities of agribusiness entities. Its development is due to the evolutionary change in the approach to assessing the value of companies and determining the factors of their long-term sustainability. Integrated reporting gives advantages to business units however, its implementation involves some difficulties. The transition to integrated reporting requires the company to make some significant reforms, efforts and costs within the following processes: 
1. Disclosure of business strategy and business model content (description of activities context (macroeconomics, legal, social); breakdown of resources; description of key factors of market growth/fall; relationship between strategic aims and business model)

2. Report quality and verification (interation between stakeholders regarding the reporting and public verification, organization of internal data in integrated reporting, external audit execution of non-financial information, as well as organization of internal interaction and increase of staff motivation as a part of process preparation of integrated reporting);

3. Reformatting of some proprietary documents and business processes;

4. Development of methodology for preparing the integrated reporting and ensuring the functioning of a formalized of information collection system and risk management system.

Preparation of integrated reporting gives agriholdings a number of competitive advantages including: creation of a better understanding of business model and performance engineering of business processes as well as increasing the confidence of investors and other stakeholders, strengthening relations with them.

Disclosure of relevant (significant) information about business strategy, business model, risks of the largest agriholdings of Volgograd region will lead both to their sustainable development and the region as a whole

\section{References}

[1] Medvedev, D. A. Russia could become one of the leading agricultural countries [Online] Available: http://importozamechenie.ru/medvedev-rossiyamozhet-vojti-v-chislo-vedushhix-agrarnyx-stran/ [Accessed: 8 Febr. 2015].
[2] Putin, V. V. Message from the President to the Federal Assembly// Bulletin of the Russian nation. 2015, Vol. 1-1, No. 39. p. 8-16

[3] Ovchinnikov, A. S., Tseplyaev, A. N., Balashova, N. N., Šilerová, E., Melikhov, V. A. Monitoring of Integrated Accounts Rendering and NonFinancial Information Disclosure to Agricultural Holdings (on the Basis of the Volgograd Region), Agris on-line Papers in Economics and Informatics. 2014, Vol. 6, No 4, p. 89-100. ISSN 1804-1930

[4] Consultant project of the international structure [Online] Available: IR// www. ir.org.ru/attachments/article/13/23.11.12 - Consultation Draft of the International Framework-Russian. pdf.] [Accessed: 8.12.2017].

[5] International standard on integrated reporting Url: http: //ir.org.ru/ attachments /article/108/13-12-08 - The-international - IR framework. docx_en-US_ru-RU.pdf (Accessed: 11. February 2017);

[6] International standard on the integrated reporting. [Online]. Available at: http://www.pwc.ru// International Integrated Reporting Framework [Accessed: 8. April 2017].

[7] The Landscape map [Online]. Available: http://corporatereportingdialogue.com/landscape-map (Accessed: 10 May 2017);

[8] Balashova N. N. Developing the Metodology to Form Integrated Reporting of Agroholdings in the Russian Federation/ N. N. Balashova, E.

Šilerová, V. A. Melikhov// Agris on-line Papers in Economics and Informatics, 2015 number 4. p. 19-29

[9] Melikhov V.A. Recommendations on System Organization of a Coherently Integrated Reporting in Agroindustrial Holdings/V.A. Melikhov//Volgograd State University Herald. Issue. 3, Economics. Ecology 2014, No 4 (27), p.148-156

[10] Tomorrow's Business Success. [Online] Available: integratedreporting.org/wp-content/ uploads/2014/10/Tomorrows-BusinessSuccess_Integrated-Reporting-L-Oct-2014.pdf. [Accessed: 1 May 2017]

[11] Druckman, P. Integrated reporting - Gaining global momentum. [Online] Available: https://www. ey.com/ZA/en/Issues/EY-integrated-reporting-hottopics-paul-druckman [Accessed: 15 Jan 2017].

[12] Eccles, R., Krzus, M. One Report: Integrated Reporting for a Sustainable Strategy. New York: John Wiley and Sons, Inc. 2010, p. 256. ISBN 978-0470-58751-5

[13] King, M., Roberts, L. Integrate: Doing Business in the 21st Century [Online] Available: http://www. mervynking.co.za/pages/publications.htm [Accessed: 15 April 2017].

[14] Balashova, N.N. Organizational and methodological approaches to development of accounting policy for formation of integrated accounting of interrelated agricultural companies / N.N.,Balashova, V.A. Melikhov, M.A. Ovchinnikov, E.M. Egorova, E.V. Tokareva // European Research Studies Journal. -2016. -T. 19. -№ 2 Special Issue. - C. 153-160. 